\title{
A Case Study of Mindful Leadership in an Ability to Develop Focus, Clarity, and Creativity of the Buddhist Higher Education Institute Leader
}

\author{
Burmansah Burmansah ${ }^{1}$, Rugaiyah Rugaiyah ${ }^{2} \&$ Mukhneri Mukhtar $^{2}$ \\ ${ }^{1}$ Doctoral Program in Educational Management, Universitas Negeri Jakarta, Indonesia \\ ${ }^{2}$ Professor in Educational Management, Universitas Negeri Jakarta, Indonesia \\ Correspondence: Burmansah Burmansah, Doctoral Program in Educational Management, Universitas Negeri Jakarta, \\ Indonesia. E-mail: burmansah_mp16s3@mahasiswa.unj.ac.id, nyanabandhu@ekayana.or.id
}

Received: August 27, 2019

Accepted: September 21, $2019 \quad$ Online Published: September 23, 2019

doi:10.5430/ijhe.v8n6p57

URL: https://doi.org/10.5430/ijhe.v8n6p57

\begin{abstract}
The objective of this research is to describe the practice of mindful leadership at Buddhist Higher Education Institute, the Institute of Advanced Buddhist Studies - Plum Village Buddhist Monastery Upper Hamlet of France, looking at the abbot's pattern and role in developing and managing the Institute of Advanced Buddhist Studies and the monastery. This research uses the approach of qualitative research with the method of a single case study. The research data collection uses the techniques of observation, interview, and documentation study. The research procedures used in this case study consist of six steps of case study research by Robert K. Yin. The research data collection was obtained by purposive sampling and snowball sampling. Data analysis techniques are used through pattern matching, explanation making, and analyzing data time series. This research found that mindful leadership can develop concentration and be more focused and have clarity. Clarity within the leader can bring up conditions of calm and peace that give a significant effect on how to respond to an existing condition. By being calm, then the leader has clarity and creativity. This situation helps the leader to recognize what is happening and helps further to decide what to do. This decision helps leadership in responding to the situation. Mindful leadership focuses on actions and internal circumstances, not on intellectual quality. The development of the leaders' internal state is related to the behavior and emotional state of each of them. Leadership that provides democratic qualities in the delivery of opinions and decision-making processes both personally and collectively strengthen the effectiveness of his leadership, and develop essential behaviors related to emotional and social intelligence.
\end{abstract}

Keywords: mindful leadership, mindfulness, decision making, educational leader, qualitative case study

\section{Introduction}

In this $21^{\text {st }}$ century, the position of leaders is very important in the management sector to make rapid movements, especially in the education sector. Not only that, the leaders must be able to serve and develop themselves as leaders who are aware of internal, environment, and external situations. These areas of awareness include the mindfulness of philosophical, psychological, social, cultural, political, economic, ethical, technological, and internal organizations and the external environment (Luqman, Farhan, Shahzad, \& Shaheen, 2012). Leadership in education occurs when leaders take the initiative to facilitate existing conditions with the aim of implementing changes in teaching and learning. They must create opportunities to enable followers to develop personal understanding and to form social groups to enable mutual support during the process of changing. They must also have the encouragement contemplate training (Ibrahim \& Abdalla, 2017). Leaders need to appreciate and take advantage of opportunities to raise their full self-awareness about relevant traits, skills, and behaviors. Leaders must develop skills to be flexible and adaptive in a world that is full of change, uncertainty, difficulty, and pressure (G. Yukl \& Mahsud, 2010). The absence of a mindfulness leader, whether in politics, religion, organization, business, education, sports, and other institutions, also means that there is an urgent need for leaders who are competent, principled, sensitive, compassionate, and mindfulness (Go \& JE, 2015).

Today, managers and leaders of organizations can handle many things. They are competent to survive, which is why they were chosen. However, being able to endure and persevere under pressure needs to be dealt smartly and effectively. Leaders need to free themselves more on autopilot themselves. Leaders must be able to handle their roles with mindfulness, to know what they are doing, to strengthen physical and mental endurance, and to not only 
concentrate on attention but also the attention of their team or organization on the right thing. For that, the leader needs mindfulness. Mindfulness as a basis for leadership that turns attention in the unknown direction lies in solutions where organizations can create value for customers and their social environment (Koole, 2014). Mindfulness has been an important exercise for most leader's success, making leaders and teams more effective, and is also recognized as an essential skill for effective leadership (Adams, 2016; Chaskalson, 2011; Chatterji \& Zsolnai, 2016). Mindfulness is very effective and can improve the quality of work life. Mindfulness is explicitly related to various core and secondary processes that are expected to improve work outcomes, including enhancing social relations, resilience, and performance. This quality potential has many positive results related to mindfulness at work (Glomb et al., 2015). Mindfulness to pay attention to things as they are by realizing that leaders can change lives, organizations and even communities (Gonzalez, 2012). Deepak Sethi in Chatterji and Zsolnai stated that mindfulness in the workplace is a key leadership competency. Leaders need to live and lead with mindfulness, train others to be mindful, and create an organization that is mindful as well. In general, in mindfulness and mature meditation practice, there are three important skills that can be learned namely: focus, awareness, and life in the present and now. Furthermore, mental training can change the lives of individuals in many ways and make individuals more effective (Chatterji \& Zsolnai, 2016). This mindfulness practice can develop clarity and enable leaders to process changes more effectively (Beverage, DeLong, Herold, \& Neufeld, 2014). In addition, routine mindfulness practices can support large improvements in achieving goals and decision making. Thinking habits of leaders with increased creativity and leader is more likely to get the opportunity he faces (Brendel, Hankerson, Byun, \& Cunningham, 2016).

\section{Theoretical Framework}

\subsection{Leadership}

Leadership as a process that can be learned and can be owned by everyone is applied to individuals both in defined roles and naturally-owned roles. Leadership is the concept of power and the potential to influence (Northouse, 2016). Leadership is defined as a process by which the intentionally influence is given to other parties to guide, to arrange, by facilitating activities and relationships within groups or organizations (G. A. Yukl, 2010). Good leaders help individuals to get meaningful goals by helping them harmonize their thoughts and clarify the reasons behind their work. Humans need understanding to be fully involved, and good leadership meets this need (Adams, 2017a). We can understand our leadership mindset in terms of an increasingly complex level of mental and emotional awareness. While we are in one reality, we will understand the reality that is less complex but not fully understands the complex reality. We might even think that this level of understanding cannot even be credited. Therefore, leadership is a very limited personal activity that is limited by our personal paradigm or our mental state, our unique mindset (Fairholm, 1998). Leadership is also precisely defined as the process of creating change that is different from the work involved in maintaining the status quo, which is solely in management. A significant focus on self-awareness, reflection, and setting priorities in someone's life become a self-mastery which is a natural consequence for leading change in an organization (Antonio \& Jonathan, 2007).

\subsection{Mindfulness}

Mindfulness is defined as an inner presence, the quality of awareness that is often described as attention as it is (Goldstein, 2016). Mindfulness is just a certain way to give attention and awareness that arises through attention in that way. This is a way to look deeply into ourselves in the spirit of self-knowledge and understanding (Kabat-Zinn, 2005). Mindfulness deals with many aspects of workplace functions and increases attention, cognition, emotions, behavior, and physiology. Correctly, mindfulness has been shown to improve the three qualities of attention, stability, control, and efficiency (Good et al., 2016). In a mindful leadership, mindfulness is the foundation of leadership that diverts attention to unclear areas, without losing attention in the here and now (Koole, 2014). Mindfulness practice is an effective strategy to improve leadership (Wasylkiw, Holton, Azar, \& Cook, 2015). With the practice of mindfulness is learning how to become aware. The most significant part of this practice is about getting used to what is felt to be more conscious and to be better in focus to maintain mindful attention. It means that almost all activities can be used as part of the practice of mindfulness (Parth, Harris, \& Forthun, 2014).

\subsection{Mindful Leadership}

Mindful leadership is about the flexibility of thought and action. It is also about to end the autopilot behavior and habits and being the best that can be done at any given moment between mind and leadership and focus on the moment and realize it (Adams, 2017b; Beverage et al., 2014). Mindful leadership is based on a strong foundation of resilience. It strengthens the ability of leaders to deal with various things and changes. It also relates to the ability to investigate, innovate, and find new ways from a shared perspective. Mindful leadership is positively related to overall job performance and also related to employee's welfare and shows the potential role to lead organizations 
with mindfulness so leaders can organize themselves and their teams and organizations more effectively (Koole, 2014; Reb, Chaturvedi, Narayanan, \& Kudesia, 2018). Mindfulness practices affect every area of leadership in a certain way because it increases self-awareness, attention control, other aspects of mental functioning, and everything we do or fails to do is the result of how effective the mind functions. Therefore, increasing self-awareness is the essential leadership skill we can develop. We can conclude that the practice of mindfulness is the highest habit of success and spending time to practice attention is the best investment we can make because it is positive. It also gives so much impact on the field of superior leadership (Tenney \& Gard, 2016). Great leaders are awake, aware, and in harmony with themselves, to others, and the world around them. They are committed to their beliefs, stand firm in their values, and live a full and passionate life. Great leaders and emotionally intelligent and their mindfulness: they try to live mindfulness of self, others, nature, and society (Boyatzis \& McKee, 2005). Mindfulness leaders embody leadership presence by fostering focus, clarity, creativity, and compassion in serving others (Marturano, 2014).

\subsection{The Ability of Leaders to Develop Focus, Clarity, and Creativity through Mindfulness Practices}

Mindfulness can direct leaders to realize that there is a strong pull to react with focused attention (focused and distributed) when in stressful conditions, in the dynamics of awkward conversations - so it does not become complicated, in reaching skilled collective agreements, and the effect of negative overload information. Positively, mindfulness can improve performance and creativity, improve relationships and knowledge through cognitive mechanisms, such as improving moods, and more efficiently in solving problems based on previous experience (Capurso, Fabbro, \& Crescentini, 2014; Kolowca, 2016). Mindfulness provides an experience to be calm and spacious that directs the balance of mental qualities in the present and now (clarity), peaceful and focused so as to allow the current situation for ideas and creativity to flow and we are in this process of creativity as a whole - a reduction in excessive thinking and mental rejection (Colzato, Ozturk, \& Hommel, 2012; Mansi, 2011; Pritchard, 2015). Creativity is a central component of the capacity for critical reflectivity (Dawson, 2003) and essential skills in maintaining and developing 'our place' in this economic world (Leavitt, 2016). Mindfulness individuals experience increased creativity because they can selectively access greater information, both externally and internally (Kudesia, 2015).

A leader who incorporates a mindfulness strategy in leadership practices can provide emotional support and guidance for others by developing mindfulness practices continuously. Not only that, leaders can help organizations and individuals to find balance and well-being in the workplace through mind training which enables people to reconnect with inner wisdom, clarity, purpose, authenticity, self-confidence, endurance, and pleasure. So, it is possible to start working with all the pressures and problems, and by encouraging us to be fully involved with ideas and live in the present and now (Chatterji \& Zsolnai, 2016; Rishel, 2015). By having mindfulness, people can change lives, organizations, and even communities (Gonzalez, 2012). Self-awareness is the essential leadership skill we can develop. It also influences every other aspect of leadership, especially in the matters of sharpness and emotional and social intelligence (Tenney \& Gard, 2016). The foundation and foundation of a mindful leadership framework are seen in the development of mindfulness (focus and awareness) that enables high self and other parties as well as possible in terms of leadership (Hougaard, Carter, \& Coutts, 2016).

The mindfulness leader requires an understanding of someone's internal compass. Mindfulness allows a leader to respond to situations as they arise to respond to the reality of constant change with calm and focus. It also helps the leaders to have the presence of mind to deal with the reality of any situation and a leader whose mindfulness is apparent in his communication. Those they lead to know that decisions are made from places with awareness, integrity, and courage (Gonzalez, 2012). To be mindfulness is only a matter of being wise or attentive with contexts that produce new knowledge about the multidimensional nature of human capacity. This phenomenon is something that the 21st-century leaders must pay attention to it. Breakthroughs in knowledge allow more directed leadership influence on others towards achieving goals - an approach that pays more attention to how best to grow traits and abilities towards achieving needs (Dickmann \& Stanford-Blair, 2009). A mindfulness leader can integrate awareness into daily work practices such as better managing himself, meetings, decision making, and mindfulness project management (Adams, 2016). It does not stop there. As a leader, creativity is needed to deal with unexpected situations. Creativity in solving problems has some slow time for the brain and mind that is currently giving better ideas. Creative solutions and ideas have an opportunity that appears better when the mind is not in a complicated situation with various kinds of work (Marturano, 2014). Dynamic and visionary leaders spend most of their time to work in the mental approach mode. By doing so, it maximizes options or encourages creative solutions. The same thing can be applied to decisions. Mindfulness helps to grow a conducive mindset approach for a good decision making (Adams, 2016). 


\section{Methodology}

\subsection{Setting}

The research was carried out at the Institute of Advanced Buddhist Studies (Institut Des Hautes Etudes Bouddhiques) - Plum Village Buddhist Monastery Upper Hamlet of France. The study was conducted in August 2017 until March 2019.

\subsection{Selection of Informants}

Interviews with the informants is an essential source of case study evidence because most case studies are related to individual events or behavior (Yin, 2009). Researchers used purposive sampling (determination of sampling based on objectives) and snowball sampling. To obtain data information, researchers set informants as targets for research conducted in accordance with the quality and characteristics of the informants. In the process of collecting data, this research involved researchers and interviewed the leaders of IABS - Upper Hamlet, Implementing Coordinators, Daily Board of Management, Dharma Teachers, Students (Monks, Nuns, Sramanera, and Sramaneri). Those who were involved in this research are listed in the following table:

Table 1. Research Informants

\begin{tabular}{lll}
\hline Code of Informant & Status & Designation \\
\hline $\begin{array}{l}\text { A-CPH } \\
\text { (Key Informant) }\end{array}$ & Dharma Teacher & $\begin{array}{l}\text { The Abbot (Leader) of IABS - Plum Village } \\
\text { Buddhist Monastery, Upper Hamlet, France }\end{array}$ \\
\hline 1-TDK & Bhikshu & $\begin{array}{l}\text { The Coordinator of Caretaking Council } \\
\text { The Coordinator of Short-term Education and } \\
\text { Training Program }\end{array}$ \\
& Bhikshu & The Coordinator of IT and Website \\
3-TDF & Sramanera & Dharma Teacher \\
4-CPB & Dharma Teacher & The Coordinator of Office \\
5-TDB & Bhikshu & The Coordinator of Building and Maintenance \\
6-TDT & Bhikshu & The Mentor of the Short-Term Program \\
7-TBT & Bhikshu & The Coordinator of Monastic Library \\
8-SAP & Sramanera & The Coordinator of Lay Practitioner \\
9-TFN & Lay Practitioner & The Coordinator of Caretaking Council for Lay \\
10-TTN & Lay Practitioner & Practitioner \\
& & The Mentor of the Long-Term Program \\
11-NYS & Bhikshu & \\
(Informants $)$ & &
\end{tabular}

\subsection{Research Design}

This research is a case study using a qualitative research approach that produces descriptive data in the form of written or oral words from interviews with people and the observed behavior of people. The purpose of using this case study method is to understand real-life phenomena in-depth (Yin, 2009). In this study, researchers used a single instrument case study, in this case, the mindful leadership of the leader of IABS - Plum Village Buddhist Monastery Upper Hamlet of France. In a single instrument case study: the researcher focuses on an issue or problem and then chooses one limited case to describe this problem (Creswell, 2007).

\subsection{Research Procedure}

The research procedures used in this study consisted of six research steps (Yin, 2009), namely: plan, design, prepare-share, collect-design, analyze-collect or collect analyze, and share. 


\subsection{Data Collection Technique}

Data collection techniques were done by participant observation, in-depth interview, and documentation. Data collection activities were collected from extensive forms, documentation and archival records, interviews, observation, and physical artifacts (Yin, 2009). The tools in this study were not used because it was not mass-produced and the resource persons of the researchers were policymakers and policy actors at the Institute of Advanced Buddhist Studies - Plum Village Buddhist Monastery, Upper Hamlet of France.

\subsection{Data and Data Analysis Technique}

Data analysis procedures include testing or testing data validity, grouping data according to sub-focus, combining data in the form of matrix or tables, or recombining the evidence that has been obtained, and to draw conclusions based. Analysis of evidence (data) consists of testing, categorizing, tabulating, or recombining the evidence to show the initial proposition of a study. Three data analysis techniques are used through pattern matching, making explanations, and analyzing time-series data (Yin, 2009).

\section{Results}

The characteristic of mindful leadership is the ability of leaders to develop focus, clarity, and creativity through the practice of mindfulness. These characteristics are divided into the practice of mindfulness, directing attention to the present, daily actions of mindfulness, and creative ideas and solutions. The research findings revealed by the informants, namely:

\subsection{Ability to Develop Focus}

In brief, this section will describe research findings on how A-CPH can develop focus and be able to integrate the constructs of mindfulness practices in all activities with leadership actions in work life and service at IABS - Plum Village Buddhist Monastery Upper Hamlet of France through the practice of mindfulness. According to the informants, one of the factors that determine the ability of A-CPH to develop and maintain focus is to carry out formal and informal practices that are carried out daily on an ongoing basis. As expressed by 1-TDK namely:

We have home hamlet days, mindfulness days, lazy days, different types. But, in general, the formal schedule is basically a schedule that helps one to live a mindful existence or a mindful life in every single moment of the day that the possibility is there for us to infuse mindfulness in every single thing from the moment we wake up to drinking tea. And mindfulness to sitting, meditation with the Sangha, walking meditation, eating meditation. Yeah, so the formal schedule is something that sort of facilitates us to live a mindful life or have a mindful existence.

A-CPH follows a formal practice of mindfulness living, such mindfulness sitting, mindfulness walking, mindfulness eating, total practice of relaxation, and a mindfulness day living with others collectively. There is also a 'lazy day' for the leaders in which they were not burdened by the working schedule. It gives them a space to run a full day free without being tied by any particular schedules. The habit of morning tea can even be a practice of tea meditation-informal practice to develop mindfulness living by A-CPH. In line with the statement, 2-TBH also expressed that $\mathrm{A}-\mathrm{CPH}$ is a mindful leader because he is a mindfulness practitioner. A-CPH conducts practice formal by following the IABS community schedule routinely from morning until night. Not only that, A-CPH also follow informal practice outside the routine schedule in IABS, especially when he is in his own home such as when having tea together, cleaning his room, etc.

The leader of the mindfulness, Abbot, is also practitioner of mindfulness. So basically, he's also part of the community and he practices what is practiced by the community. So, he also follows the schedule. From the morning until the evening we also have all schedule to have us to cultivate mindfulness, but also as a person we also have personal practice outside of the regular schedule. For example, we also practice in our room, when we drink tea, when we clean up our room, and other things.

The 3-TDF informant also provides information, if in addition to carrying out these basic formal practices, A-CPH also conducts an informal practice of writing calligraphy about writing relating to the practice of mindfulness, "I think it's mainly practices like sitting meditation, walking meditation, eating meditation, and... but I know he also writes calligraphy about mindfulness practice." In general, we can examine that A-CPH does two practices of mindfulness in its daily life. First, formal practices - practices that have become routine schedules for basic training in mindfulness and secondly, informal practices - which are carried out on a daily basis without being scheduled. This was confirmed by informant 6-TDT that, "the daily practice of the abbot, yeah, practice of mindfulness, we have two different kinds of practice. The first one is the formal practice, and the second one is the application in our daily life." Information from these informants concluded that the mindfulness practice undertaken by A-CPH is an 
ongoing exercise both formally and informally that is individual and collective. Conscious practices routinely cultivate entrenched habitual energy so that they become part of A-CPH. Formally conscious practices are routinely practiced and have become an organizational culture at IABS - France. This formal practice is supported by informal practices that enhance the practice of mindfulness undertaken by A-CPH. Informant 2-TBH further said that A-CPH in practice when carrying out its responsibilities as the leader of the institution, he would integrate mindfulness constructs with work activities and services that he lived. This practice is not only personal for him but also collective.

Everyone actually integrate himself in mindfulness and all activities. So, the abbot is also the same. It means he's also the practitioner of mindfulness. Then, he also practices mindfulness by himself or as a collective. So, when he has service or work in the community, as a group, then automatically, he also applies mindfulness inside the service. Because that also can apply mindfulness in the working area.

Furthermore, information from 3-TDF informants revealed that one of the practices carried out by A-CPH was in the relationship of mindfulness constructs in the actions of its leadership by maintaining focus so as to create mindfulness in itself and the parties.

I'm sure that in general the quality of mindfulness is a big support but also in a way this facilitates meeting. We use the bell which is something that helps us all to be mindful, or inviting the bell at the beginning of a meeting. During the meeting, we are all silent, follow our breathing. So it's a moment everybody in the meeting kind of strengthen their mindfulness too. And you read contemplation before meetings so that we enter the meeting with the right attitude and with the intention to listen to each other and solve things together and make decisions that work out for everybody.

In general, the quality of mindfulness is a great support in facilitating meetings conducted by A-CPH. One of the tools used to start a meeting is a bell or bell, which is very helpful. During the meeting, those who do not speak will practice silence and realize their breathing. The moment at the meeting was also used as a practice to strengthen his awareness. It does not stop there, before the meeting the leader will read the reflections before the meeting so that when the meeting takes place the meeting participants have a right attitude and intention to listen to each other, resolve various things together, and make decisions that are suitable for all parties. It was reinforced by the 4-TPB informant by giving a concrete example of how A-CPH led a meeting in its role as the leader of the institution when coordinating and giving direction to the daily implementing coordinators at IABS - Upper Hamlet France.

Through the information obtained from the informants, it can be understood that A-CPH strives for the practice of mindfulness in each of its leadership activities. Starting from integrating into the self and bringing the quality of mindfulness in the collective development at the IABS - Upper Hamlet France. Every activity is supported by supporting tools such as mindful contemplations and bells as a reminder for himself and other parties. It is done continuously in the attitudes and actions of leadership in the institution he leads. It does not stop there, technically, A-CPH strives to maintain conscious energy within itself and other parties with various systematic efforts as a conscious leader by maintaining continuity in various activities that include the work and service process carried out by a leader. Besides, in terms of manifesting his practice clearly, the informant saw that A-CPH integrated the practice of mindfulness for himself, also to support and help other parties. This information was said by informant 5-TDB saying that:

The Abbot is really embodying the practice. So I can see that he really integrates the practice of mindfulness for himself first so that he can help people and help the brothers around, especially, to really integrate the practice of mindfulness and I've been benefited a great deal from his presence.

Through this information, it can be seen that A-CPH practices mindfulness not only for itself but also on how it can help and support others in its leadership to become mindfulness in various activities carried out both personally and collectively in the community they lead. More specifically, in exploring information on integrating mindfulness practices is how A-CPH integrates mindfulness practices can be seen from the way he thinks, from what is said, how A-CPH speaks, and what he is doing and has done. This information was said by informant 6-TDT that:

The Abbot integrate the practice of mindfulness actually is related to my answer from the previous question about the practice in daily life. So basically we can recognize his practice from his thought, from his... from what he speaks, how he speaks, and about another one is how... what he did, what he does.

Through information from this interview excerpt that the process of integrating this mindfulness practice can be reflected through the thoughts, speech, and leadership actions of the IABS - Upper Hamlet France guild carried out in leading and daily practices. Through information gathered from key informants and informants that A-CPH conducts formal and informal practices in its leadership and daily life. It shows the ability of A-CPH to develop, 
maintain and maintain focus at all times inside and outside itself through the practice of mindfulness that is continuous and systematic. Mindfulness practice is not only done personally but also collectively. These are interrelated and support one another.

\subsection{Ability to Sustain Clarity}

The ability to be more focused leads to clarity in mind and the heart of A-CPH. Focus helps to find oneself fully, to see clearly what is in front of him, and to choose how to respond to it. It also means being focused and distributed with clearer attention and concentration within him. In this case, A-CPH exerts his ability to keep and maintain clarity within himself. A-CPH's ability to develop sharp clarity not only sees clearly around him but also sees clearly inside him. For A-CPH to achieve the goal of leading with courage and integrity, it also requires the ability to see the current state of the environment.

According to informant 3-TDF said that with mindfulness A-CPH can develop concentration and become more focused, then A-CPH is more aware of his thoughts and not carried away. So by being more focused, A-CPH has more clarity - it is clearer what is happening to him and the decisions that must be made.

I think by being mindful, sustaining our mindfulness for a longer period, we develop concentration, more focus. And also because we try to be aware of our thoughts but not get carried away with them. So more focus and to have more clarity - more clearly what is going on in our lives, some decisions we have to make.

Based on the interview above, the information provided illustrates that A-CPH who practices mindfulness exercises will be able to develop more focused concentration and attention. With the ability of A-CPH developing a focus within him, he is also able to bring clarity in him. Clarity helps to see the phenomena that arise in themselves more clearly and to know what decisions must be taken to respond to these phenomena. Informant 1-TDK said that A-CPH saw things around him with a mindfulness perspective for the collective interest. This is by directing his and his collective views in a directed and clear manner. This action is carried out with informal mindfulness practices, namely with the practice of informal tea drinking meditation. This practice is carried out to maintain clarity within the leader and the people around him. This practice shows A-CPH not only for itself but for other parties as well.

So personally what I find is with the Abbot here is that he at times has a sort of standoff approach, and at times he sees that he needs an infused approach. So he's... like I said before, he has an overview of the whole Sangha. He can sort of go in and out and sort of gage with the Sangha needs, but he also has that for each individual brother. So sometimes I see that he comes more towards me and says, "Oh, let's sit and drink tea." And he offers advice on something that needs to happen and whatever. And then other times he might just step away and let you take care of everything for a few weeks, you know, or a few months even. And then, suddenly he might come again. So he is able to... I find the Abbot is able to very clearly see when he needs to step in. What he tries to do mostly is offer brothers total trust in their practice.

The same thing was expressed by 2-TBH informants saying that A-CPH as a mindfulness practitioner, he has the capacity to return to himself and 'stop' when needed to 'stop'. Stopping here is defined as the practice of returning inside and directing to mindfulness when an unfavorable situation. Because in some unfavorable situations earlier, it will cause stress or anxiety, then A-CPH can stop these emotions, so he calmed himself. So, the practice of mindfulness helps A-CPH to recognize what is happening and helps further to decide what to do. This decision will assist A-CPH in responding to this situation. By being calm, A-CPH has clarity and creativity because creativity comes from relaxation and calmness.

The Abbot as the practitioner, he must be able to come back to himself and stop whatever needs to be stopped. For example, when we have a certain case that creates stress or anxiety, with the practice of mindfulness, he's able to stop that emotion to develop; so that, he can calm himself down. So, the mindfulness can help us to recognize what is happening and to help us to decide what to do. But, that decision that help us what to do is to help us to calm ourselves down. By calming down, then we have clarity and creativity. Because the creativity is based on the relaxation and the calmness.

Furthermore, 2-TBH informant added that by stopping and recognizing what was happening, this much helped A-CPH to speak lovingly and to be able to listen deeply to the situation at hand. It does not make A-CPH react too fast.

By the art of stopping and the art of recognizing what is happening. Then, it helps the practitioner to speak more lovingly and to listen more deeply to the situation that is happening; so that, we are not too reactive. So, the Abbot also practices the same thing. 
Based on the information conveyed by informants, it is said that the clarity within A-CPH starts from the ability to develop focus through formal and informal mindfulness practices that provide quality of peace and tranquility. Quality makes leaders able to 'stop' under certain conditions; so that, A-CPH has a time lag to choose the best way to respond to problems that arise. It is not only at the personal level, but also able to be applied collectively in his leadership. Clarity within A-CPH will bring out the creativity in and around. Creativity arises because the quality of personal and collective clarity of leaders comes from the ability to relax and to bring the same thing to other parties. This creativity is an aspect that helps bring up creative ideas in the decision-making process in various matters carried out by A-CPH.

\subsection{Ability to Develop Creativity}

Clarity leads A-CPH to the state of which he has room within him to come up with creative ideas and solutions when the mind is not overwhelmed by overwhelming busyness with a piling list of work. The mind needs a few moments to pull out of the analytical mind for innovative and creative solutions to emerge. In the process, A-CPH can allow more room for this creativity to exist through the practice of mindfulness. As the 1-TDK informant said that A-CPH possibly allows great space and patience within him in certain situations. It allows A-CPH to direct the various situations and opportunities in front of him in the right direction. By having the time to choose and to see clearly, he can get out of the existing difficulties.

He offers is huge amount of space, patience, and he sees that... I feel that he sees that we're all going in the right direction but if we just take time, you know..... I feel that's what he offers, and with that space, one can really go through their difficulties.

Based on the statement above, the informant said that A-CPH strives for 'space' and patience within him so that it can see, to understand, and to direct various situations and opportunities clearly in the right direction. How to respond problems of his followers and set an example are believed to be the result of the practice undertaken by A-CPH. Furthermore, informant 3-TDF said that in making decisions either in a meeting or another purpose, A-CPH would practice listening deeply and speaking with love. This practice is aimed to help to maintain harmony and to be able to make decisions together, bringing all parties to the collective energy despite a conflict of interest at the time.

We have the practice of deep listening and loving speech. I think that is both for the abbot and also for the people in the meetings, it's important. Way of listening and speaking to help keep the harmony and to be able to make decisions together, bring people together even if there are maybe conflicting interests.

The process of applying mindfulness through creativity that gives rise to creative ideas in decision making, as explained by the 6-TDT informant is below:

When the difficult situation coming, then we try to practice stopping. It means that we don't let the problem overwhelm us. So we try to stop not to think too much about the problem. We just come back to our self, to our breathing. And then by come back to our self, we will have space between our self and the problem itself, and the space give us opportunity to look deeply into that problem. So from this moment sometimes the creative idea will come out. And, yeah, it's not only, as I said before, it's not only from the leader, from the abbot, but also from the entire community. When such kind of creative idea come out, then the next process is that... So after we simply leave out the problem and the creative way to solve that problem, the abbot will integrate that creative idea and come to the decision-making.

The 7-TBT informant also said that, "every practitioner practicing mindfulness and relaxation will achieve creativity." Based on all information above, A-CPH runs mindfulness practices and can set examples and role models for various parties. Mindfulness practices help in the process of responding to situations and conditions with a variety of existing problems and preoccupations. Mindfulness practice gives pause and time to choose how to respond to a particular matter. Through this mindfulness practice, A-CPH integrates creativity or creative ideas in decision making.

\section{Discussion}

The research analysis result indicates that the characteristics of mindful leadership practiced by leaders with the ability to develop focus, clarity, and creativity are carried out through the development of mindfulness practices. The ability of leaders to develop and maintain focus is by carrying out formal and informal practices which are carried out daily on an ongoing basis such as the practice of mindful sitting, mindful walking, mindful eating, total relaxation practices, and one day of individual and collective conscious living. Also, there is a day without a schedule 'lazy day' where the leader is not charged by the existing work schedule and provides space for him to undergo a full day without being bound by certain activities. Besides, the habit of drinking tea in the morning is made as a tea or drinking meditation-an informal practice to develop a life of mindfulness. It has become one of the uniqueness in the practice of mindfulness. A-CPH undergoing formal practice personally also follows the community 
schedule at IABS - Upper Hamlet France routinely from morning to night collectively. The leader also undertakes informal practices outside the regular schedule at IABS - Upper Hamlet France such as practicing in his residence when drinking tea together, cleaning the room, and others. It shows that the practice of conscious awareness can routinely cultivate entrenched habitual energy so that it becomes part of A-CPH. Formally, conscious practices are routinely practiced and have become an organizational culture at IABS - Upper Hamlet France. This formal practice is supported by informal practices that enhance the practice of mindfulness undertaken by A-CPH. Both types of practice are the foundation of mindfulness practices that are integrated into leadership actions through their daily activities. Mindfulness is developed through formal and informal practices. Formal practice is an investment of time that is explicitly done in the practice of mindfulness or meditation. Whereas, informal practice is a process of 'weaving' the practice of mindfulness in existing routines through involvement in moments of mindfulness such as mindful eating (Birtwell, Williams, van Marwijk, Armitage, \& Sheffield, 2018).

From the comparison of mindfulness practices carried out by A-CPH with leaders and other practitioners through the results of previous research, there are many practices that are quite different. One of them is a day without a schedule 'lazy day', happiness meeting, beginning a new and day of mindfulness becomes interesting because it only exists at IABS - Upper Hamlet France. No previous research has mentioned this mindfulness practice both formally or informally. Moreover, the leader also held a collective day of mindfulness as an informal practice of mindfulness once a week. This type of informal practice is open to the collective and the public. This one-day practice without a schedule and one day of mindful living are seen as an informal practice which is very helpful for developing focus so that it can get out of the autopilot habit that is not mindfulness individually. During formal mindfulness exercises, turning someone's attention to present moment experiences can help a person break away from problematic ruminative thought processes. The nature of mindfulness implies an expansive, evaluative, ineffective problem-solving orientation, contrary to focus (Hawley et al., 2014). The effects of informal practice are most prominent in the dimensions of the state of mindfulness. Therefore, it appears that daily activities approached with deliberate and mindfulness can improve the state of focus (Hanley, Warner, Dehili, Canto, \& Garland, 2015).

Furthermore, in the practice of mindful leadership, the ability to develop focus by the leader by directing himself is always on the attention these days and currently on carrying out his daily activities so that he can realize what is being done without anxiety and concern. This effort is to bring calm within. By being mindfulness for a longer period of time, the leader can develop concentration and be more focused. The essential thing in the mindfulness dimension is for leaders to develop focus as part of directing the welfare of their followers (Arnold \& Walsh, 2017). The leader will not easily and quickly to react to something happening in front of him. Mindfulness makes leaders more calm and clear so that they can make small decisions to adjust to the challenges that lay before them. It has an impact and influence that is different from the leadership reaction in general. Mindfulness practices provide clarity and 'space' to steer mentally in the present, be calm and focused. Being present allows ideas and creativity to flow because there is calm, 'space', and clarity within. This mindfulness practice provides an encouraging and non-stressful mood (Pritchard, 2015). Mindfulness practices not only help leaders increasing focus on their thought patterns and emotional states, but also affect the way they interact with others. Intentional long-term focus helps to improve the flexibility and adaptability of leaders (Schaufenbuel, 2014).

From the discussion of research results on the characteristics of the ability to develop focus, it can be concluded that there is no significant difference from the findings of research conducted by researchers with previous studies. This finding can clearly explain how the process of integrating the mindfulness practices carried out by the leaders reflected through the thoughts, words, and actions of his leadership in leading and daily practices. It illustrates that previous research concludes on experiences when carrying out formal and informal mindfulness practices as real experiences but this study illustrates how leaders practice mindful living in daily activities to develop and maintain focus in their leadership through a variety of formal and informal mindfulness practices. The practices carried out by the leaders are far more concrete. Also, there are several informal practices that show how to carry out mindfulness practices for leaders in busyness such as one day without a schedule and one day of mindfulness. It becomes a new picture of the development of mindfulness practices for leaders and complements the results of previous studies. With mindfulness, the leaders can develop concentration and become more focused. So, he becomes more aware of his thoughts and is not easily carried away. By being more focused then, he has more clarity. With the ability of leaders to develop a focus within them, they are also able to bring clarity in themselves. Clarity within the leader can lead to conditions of calm and peace that have a significant influence on how to respond to an existing condition. By increasing mindfulness and focus at the moment, attention can help with listening and communication skills (Loubier \& Munoz, 2017). This situation helps to look deeper into what is being faced and understand the problem; so that, it 
can determine the next step with a focused leadership attitude and has clarity within. With clarity, the leaders can see more clearly the phenomena that arise within and know what decisions are taken to respond to the phenomenon.

Mindfulness practice is satisfying because it reveals many aspects of life that are usually ignored and unrealized by people. It also provides clarity. This clarity can express deep emotions that are not pleasant to deal with, but dealing with these feelings is a journey to become mindfulness (Koller, 2017). From the discussion of the characteristics of mindful leadership regarding the ability of leaders to maintain clarity is in line with previous studies that when leaders can develop a focus within them, then within the leader there will be a concentration that brings clarity. Clarity within the leader can significantly influence how to respond to an existing condition. Furthermore, the leader, as a practitioner of mindfulness has the capacity to return to himself and 'stop' when needed to 'stop'. Stopping here is defined as the practice of returning inside and directing to mindfulness during an unfavorable situation. During a number of unfavorable situations, stress or anxiety can arise. In this situation, the leader can stop the emotions so that he can calm himself down. Mindfulness can be a tool to foster mental clarity and inner calm as well as insight and creativity (Pritchard, 2015). So, the practice of mindfulness can help leaders recognizing what is happening and help further to decide what to do. This decision helps leadership in responding to the situation. By being calm, the leader has clarity and creativity as creativity comes from relaxation and calmness. Practicing mindfulness or meditation at work can optimize the climate of creativity. It can bring up the mindfulness of leadership in the workplace that is connected to the benefits of personal and organizational creativity. It gives understanding and experience to be potential advantages and relationships (Mansi, 2011). This creativity becomes an aspect that helps to bring up creative ideas in the decision-making process in various things done by the leadership. The leader mobilizes his ability to maintain and maintain clarity within himself. The effect on creativity is only limited to performance directly after meditating. It must grow the leadership knowledge about possible cognitive mechanisms, such as improved moods, better attention (focused or distributed), or more efficient coping with disturbances of past experiences, which will influence creative thinking (Capurso et al., 2014). The ability to develop sharp clarity not only sees clearly around outside self but also sees inside. To achieve the goal of leading with courage and integrity, it also requires the ability to see the current state of the environment. With mindfulness, the leaders can develop concentration and become more focused. They become more mindful with their thoughts and do not easily carry away. Creative thinking is related to critical reflection; this will help to understand more deeply. Creativity, like the mind, takes a moment and gives rise to space to strengthen mindfulness. Creativity is a central component of critical reflection capacity (Dawson, 2003)

\section{Conclusion}

Based on the research results and the discussion on mindful leadership with the characteristics of the ability of leaders to develop focus, clarity, and creativity undertaken by A-CPH can be seen and applied comprehensively in the attitudes and actions of its leadership. It also shows the ability of leaders to develop and maintain focus by carrying out formal and informal practices daily on an ongoing basis individually and collectively. With mindfulness, A-CPH can develop concentration and becomes more focused and has clarity. The clarity within A-CPH can bring about conditions of calm and peace that give a significant influence on how to respond to an existing condition. This situation helps to look deeper into what is being faced and understand the problem so that it can determine the next step with his leadership attitude. Mindfulness or giving attention to what is happening in the present and now is essential for becoming an effective leader (Rauzi, 2013). Under these conditions, A-CPH can see more clearly the phenomena that arise and know what decisions must be taken to respond to the phenomena and challenges that are being faced. Mindful leadership A-CPH shows that leadership that focuses on the actions of leaders and internal conditions rather than on intellectual quality. The development of the internal state of A-CPH is related to behavior and emotional state of self. A-CPH also provides democratic qualities in the delivery of opinions and decision-making processes both personally and collectively, strengthens the effectiveness of its leadership, and develops essential behaviors related to emotional and social intelligence.

\section{Acknowledgments}

The researcher would like to thank the research funding support provided by the Yayasan Triyanavardhana Indonesia - Wihara Ekayana Arama. 


\section{References}

Adams, J. (2016). Mindful Leadership for Dummies. (M. Grazier, Ed.). West Sussex: John Willey \& Sons, Ltd.

Adams, J. (2017a). Exploring the Benefits of Mindful Leadership. Retrieved June 7, 2017, from https://www.dummies.com/business/management/mindful-leadership-dummies-cheat-sheet/

Adams, J. (2017b). Mindful Leadership for Dummies Cheat Sheet. Retrieved June 7, 2017, from https://www.dummies.com/business/management/mindful-leadership-dummies-cheat-sheet/

Antonio, M. \& Jonathan, G. (2007). The Leadership: The Key Concepts. London: Taylor \& Francis e-Library.

Arnold, K. \& Walsh, M. (2017). Mindful Leadership and Employee Well-Being: The Mediating Role of Leader Behaviours. In Leading to Occupational Health and Safety: How Leadership Behaviours Impact Organizational Safety and Well-Being, 235-254. St. John's, NL, Canada. Retrieved from https://www.researchgate.net/publication/330409339_Mindful_leadership_and_employee_well-being_The_med iating_role_of_leader_behaviours

Beverage, S., DeLong, K., Herold, I. M. H. \& Neufeld, K. (2014). Mindful Leadership Defined and Explained. Advances in Librarianship Journal, 38, 21-35. https://doi.org/10.1108/S0065-283020140000038000

Birtwell, K., Williams, K., van Marwijk, H., Armitage, C. J. \& Sheffield, D. (2018). An Exploration of Formal and Informal Mindfulness Practice and Associations with Wellbeing. Mindfulness, 2019(10), 89-99. https://doi.org/10.1007/s12671-018-0951-y

Boyatzis, R. \& McKee, A. (2005). Resonant Leadearship. Boston: Harvard Business School Press.

Brendel, W., Hankerson, S., Byun, S. \& Cunningham, B. (2016). Cultivating leadership Dharma: Measuring the impact of regular mindfulness practice on creativity, resilience, tolerance for ambiguity, anxiety and stress. Journal of Management Development, 35(8), 1056-1078. https://doi.org/10.1108/JMD-09-2015-0127

Capurso, V., Fabbro, F. \& Crescentini, C. (2014). Mindful creativity: the influence of mindfulness meditation on creative thinking. Frontiers in Psychology, 4(January), 1-2. https://doi.org/10.3389/fpsyg.2013.01020

Chaskalson, M. (2011). The Mindful Workplace : Developing Resilient Individuals and Resonant Organizations with MBSR. UK: John Wiley \& Sons, Ltd.

Chatterji, M. \& Zsolnai, L. (2016). Ethical Leadership: The Indian Way. London: Palgrave Macmillan. https://doi.org/10.1057/978-1-137-60194-0

Colzato, L. S., Ozturk, A. \& Hommel, B. (2012). Meditate to create: the impact of focused-attention and open-monitoring training on convergent and divergent thinking. Frontiers in Psychology, 3(April), 1-5. https://doi.org/10.3389/fpsyg.2012.00116

Creswell, J. W. (2007). Qualitative Inquiry \& Research Design: Choosing Among Five Approaches (2nd ed.). California: SAGE Publications, Inc.

Dawson, J. (2003). Reflectivity, Creativity, and the Space for Silence. Reflective Practice, 4(1), 33-39. https://doi.org/10.1080/1462394032000053512

Dickmann, M. H. \& Stanford-Blair, N. (2009). Mindful Leadership: A Brain-Based Framework Second Edition (2nd ed.). California: Corwin Press.

Fairholm, G. W. (1998). Perspectives On Leadership : From the Science of Management to Its Spiritual Heart. USA: QUORUM BOOKS.

Glomb, T. M., Duffy, M. K., Bono, J. E., Yang, T., Glomb, T. M., Duffy, M. K. \& Bono, J. E. (2015). Mindfulness at Work. Research in Personnel and Human Resources Management, 30, 115-157. https://doi.org/10.1108/S0742-7301(2011)0000030005

Go, I. \& JE, O. (2015). Impact of Leadership Style on Organization Performance : A Critical Literature Review. Arabian Journal of Business and Management Review, 5(5), 1-7. https://doi.org/10.4172/2223-5833.1000142

Goldstein, J. (2016). Mindfulness: A Practical Guide to Awakening. Canada: Sounds True.

Gonzalez, M. (2012). Mindful Leadership: The 9 Ways to Self-Awareness, Transforming Yourself, and Inspiring Others. Ontario: Jossey-Bass.

Good, D. J., Lyddy, C. J., Glomb, T. M., Bono, J. E., Brown, K. W., Duffy, M. K. \& Lazar, S. W. (2016). Contemplating Mindfulness at Work: An Integrative Review. Journal of Management, 42(1), 114-142. 
https://doi.org/10.1177/0149206315617003

Hanley, A. W., Warner, A. R., Dehili, V. M., Canto, A. I. \& Garland, E. L. (2015). Washing Dishes to Wash the Dishes: Brief Instruction in an Informal Mindfulness Practice. Mindfulness, 6(5), 1095-1103. https://doi.org/10.1007/s12671-014-0360-9

Hawley, L. L., Schwartz, D., Bieling, P. J., Irving, J., Corcoran, K., Farb, N. A. S. \& Segal, Z. V. (2014). Mindfulness practice, rumination and clinical outcome in mindfulness-based treatment. Cognitive Therapy and Research, 38(1), 1-9. https://doi.org/10.1007/s10608-013-9586-4

Hougaard, R., Carter, J. \& Coutts, G. (2016). Mindful Leadership: Achieving Results By Managing the Mind. Leader to Leader, 2016(79), 49-56. https://doi.org/10.1002/lt1.20218

Ibrahim, A. A. \& Abdalla, M. S. (2017). Educational Management, Educational Administration and Educational Leadership : Definitions and General concepts SAS Journal of Medicine ( SASJM ) Educational Management, Educational Administration Leadership: Definitions and General concepts and. SAS Journal of Medicine (SASJM), 3(6), 2454-5112. https://doi.org/10.21276/sasjm.2017.3.12.2

Kabat-Zinn, J. (2005). Full Catastrophe Living: Using the Wisdom of Your Body and Mind to Face Stress, Pain, and Illness. New York: Bantam Dell.

Koller, N. (2017). Mindful Leadership: The Impact of Mindfulness on Managers' Ethical Responsibility. Library of Zurich University. Retrieved from https://digitalcollection.zhaw.ch/bitstream/11475/7681/1/Koller_Nadine_W.MA.IB.pdf

Kolowca, M. (2016). Applying mindfulness in coaching-a way forward for effective change. Icn-Artem.Com. House of Training. Retrieved from http://www.icn-artem.com/wp-content/uploads/2017/06/2016-Mémoire-Magdalena-Kolowca.pdf

Koole, W. (2014). Mindful Leadership: Effective Tools to Help You Focus and Succeed. Amsterdam: Warden Press.

Kudesia, R. S. (2015). Mindfulness and creativity in the workplace. In J. Reb \& P. Atkins (Eds.), Mindfulness in Organizations: Foundations, Research, and Applications, 190-212. Cambridge University. https://doi.org/10.1017/CBO9781107587793.010

Leavitt, M. A. (2016). Untangling The Relationship Between Creativity And Mindfulness: One Teacher's Experience Of The Meditation Inherent In Her Creative Process. UNB Scholar Library. Retrieved from https://unbscholar.lib.unb.ca/islandora/object/unbscholar\%3A7739/datastream/PDF/view

Loubier, B. L. A. \& Munoz, G. M. (2017). Mindfulness: Tapping Into Its Power to Achieve Professional and Personal Success and Wellness. The Abstract, (Spring), 31-39. Retrieved from https://www.stearnsweaver.com/files/2017 Gisela Munoz ACMA Mindfulness.pdf

Luqman, R. A., Farhan, H. M., Shahzad, F. \& Shaheen, S. (2012). 21st Century Challenges of Educational Leaders, Way Out and Need of Reflective Practice. International Journal of Learning and Development, 2(1), 195-208. https://doi.org/10.5296/ijld.v2i1.1238

Mansi, M. (2011). Meditation and Workplace Creativity: A Potential Relationship Meditation and Workplace Creativity: A Potential Relationship. In ANZAM 2011, 1-21. Wellington, New Zealand: Australian and New Zealand Academy of Management. Retrieved from https://pdfs.semanticscholar.org/7d5d/1b49d3a05074d854b1853c969d45663d9aad.pdf

Marturano, J. (2014). Finding the Space to Lead: A Practical Guide to Mindful Leadership. USA: Bloomsbury Press.

Northouse, P. G. (2016). Leadership: Theory \& Practice Seventh Edition (7th ed.). California: SAGE Publications, Inc.

Parth, N., Harris, V. \& Forthun, L. (2014). Mindfulness : An Introduction (No. FCS2335). Florida. Retrieved from https://www.researchgate.net/publication/261528260_Mindfulness_An_Introduction

Pritchard, J. (2015). Ideation, Creativity and Mindfulness : Investigating the Influence of Mindfulness Practice on. University of Alberta Library. Retrieved https://era.library.ualberta.ca/items/3819d410-0c52-4adb-bb3e-7bbd0e29f554/view/59288617-ac54-4b5b-ac8d03ed0d56515c/Pritchard_Justin_O_201509_MDes.pdf

Rauzi, R. (2013, February 23). Tapping into the power of mindfulness. Los Angeles Times. Retrieved from http://articles.latimes.com/2013/feb/23/business/la-fi-meditation-management-20130224 
Reb, J., Chaturvedi, S., Narayanan, J. \& Kudesia, R. S. (2018). Leader Mindfulness and Employee Performance: A Sequential Mediation Model of LMX Quality, Interpersonal Justice, and Employee Stress. Journal of Business Ethics. https://doi.org/10.1007/s10551-018-3927-X

Rishel, C. (2015). The Role of Resilience and Mindful Leadership in Oncology Nursing. Oncology Nursing Forum, 42(2), 198-199. https://doi.org/10.1188/15.ONF.198-199

Schaufenbuel, K. (2014). Bringing Mindfulness to Your Workplace. UK. Retrieved from https://www.kenan-flagler.unc.edu/ /media/Files/documents/executive-development/unc-white-paper-bringingmindfulness-to-the-workplace_final.pdf

Tenney, M. \& Gard, T. (2016). The Mindfulness Edge: How to Rewire Your Brain for Leadership and Personal Excellence Without Adding to Your Schedule. New Jersey: John Wiley \& Sons, Inc. https://doi.org/10.1002/9781119249382

Wasylkiw, L., Holton, J., Azar, R. \& Cook, W. (2015). The impact of mindfulness on leadership effectiveness in a health care setting: a pilot study. Journal of Health Organization and Management, 29(7), 893-911. https://doi.org/10.1108/JHOM-06-2014-0099

Yin, R. K. (2009). Case Study Research: Design and Methods Fourth Edition (Applied Social Research Method Series Vol 5). SAGE Publications, Inc. (Fourth Edi). Thousand Oaks, California: SAGE Publications, Inc.

Yukl, G. A. (2010). Leadership in Organizations (7th ed.). New Jersey: Pearson Education, Inc.

Yukl, G. \& Mahsud, R. (2010). Why Flexible and Adaptive Leadership is Essential. Consulting Psychology Journal, 62(2), 81-93. https://doi.org/10.1037/a0019835 